\title{
CUADROS Y ESCRITURAS DE LA NATURALEZA*
}

\author{
Juan Pimentel \\ Depto. Historia de la Ciencia, Instituto de Historia, CSIC
}

\section{RESUMEN}

El aniversario del regreso de Humboldt a Europa es también el de una doble transferencia: el del Nuevo al Viejo Mundo y el de la Naturaleza al libro. Este trabajo se centra en la representación, esfera en la que la literatura descriptiva humboldtiana desempeña una labor fundamental. Estudiamos la relación entre la imagen y la palabra, entre el pensamiento visual de Humboldt y sus técnicas narrativas para animar y vivificar la naturaleza. Cuadros y Cosmos son las obras más destacadas en este terreno; Bernardin de Saint-Pierre, Goethe y Aristóteles, algunas de las claves que empleamos para descifrar dicha literatura descriptiva.

PALABRAS CLAVE: Representación, viajes, literatura descriptiva, pensamiento visual, poiesis, mimesis.

\section{SUMMARY}

To conmemorate Humboldt return journey to Europe means that of a double transference: we also celebrate how the New World was back to the Old, and how Nature back to the Book. Our focus is representation, an sphere where humboldtian descriptive literature plays a basic role. Here we study the relation between images and words, between Humboldt visual thinking and his narrative techniques in order to animate, giving life to nature. Views of Nature and Cosmos are the two main works in this field; Bernardin de Saint-Pierre, Goethe, and Aristotle, some of the keys we use to decode that descriptive literature.

KEY WORDS: Representation, travels, descriptive literature, visual thinking, poiesis, mimesis.

«He tenido la ocasión de desarrollar la idea de que los viajeros no pueden más que transportar de una comarca a otra la ciencia incompleta de su tiempo»

Humboldt, Cosmos, IV

* Trabajo realizado en el marco del proyecto de investigación «Redes, objetos y prácticas en la Ilustración española y americana», Centro de Estudios Hispánicos e Iberoamericanos, Fundación Carolina, CEHI 02/03. Agradezco a Miguel Ángel Puig-Samper su estímulo para incluirme en este dossier y seguir profundizando en el universo humboldtiano. 
«La mejor descripción es la que convierte en ojos los oídos»

Humboldt, Cosmos, II

Se cumplen ahora doscientos años del regreso de Humboldt a Europa tras su viaje americano. Fue el 10 de agosto de 1804 cuando arribó a Burdeos. Atrás quedaba una experiencia de cinco años, un viaje verdaderamente colosal tanto si atendemos a los territorios visitados como, sobre todo, si atendemos a la infinidad de trabajos y observaciones registradas o, por descontado, a la extraordinaria variedad disciplinar desplegada por el gigante prusiano. Pocos días después, el 27 de agosto, llegaría a París para instalarse en el Fauburg Saint-Germain. Delante quedaba otra empresa no menos soberana: aquilatar toda aquella experiencia y publicar sus resultados.

Es el tránsito del trabajo de campo al del estudio, la conversión de una experiencia privada y sensible del mundo en un acto de producción de conocimiento. Pues si bien el viaje es una práctica emparentada con la lectura (así lo fue para todos los hijos de la ciencia moderna: con la lectura del libro de la naturaleza) o con el experimento (con la tortura de los fenómenos naturales) ${ }^{1}$; la composición de una obra, obviamente, guarda relación con la escritura, de hecho es escritura, escritura del mundo, o mejor dicho en este caso, escritura o inscripción de la tierra (así lo indica la etimología de la palabra en cuestión: geografia) ${ }^{2}$.

En ambas tareas, tanto en la operación de viajar o leer el mundo como en la de escribirlo, nos encontramos pronto con la noción de transferencia. Los viajeros se trasladan a través de la tierra, desplazan sus cuerpos, sus instrumentos y sus conocimientos de un lado a otro - transportan de una comarca a otra la ciencia incompleta de su tiempo, según reza la fórmula de Humboldt que encabeza estas líneas-; y otro tanto puede decirse en términos generales de los científicos cuando redactan sus obras, y muy particularmente de los científicos viajeros cuando llega el momento decisivo de poner por escrito sus

1 JALÓN, M. (2004), «Los viajes y las ciencias al inicio de la modernidad», en CABORNERO, J. (ed.), Andanzas y caminos. Viejos libros de viajes, Valladolid, Junta de Castilla y León, pp. 105-125, p. 117, donde el autor apunta la etimología emparentada de la voz viaje con desvío, penalidad, tortura (travel). El carácter experimental del viaje lo hemos tratado en Pimentel, J. (2003), Testigos del mundo. Ciencia, literatura y viajes en la Ilustración, Madrid, Marcial Pons, pp. 47-71.

2 Una interesante reflexión al respecto en PARdo, J.L. (1991), Sobre los espacios. Pintar, escribir, pensar, Barcelona, Ediciones del Serbal, pp. 61 y ss. 
relaciones, descripciones o teorías fruto de sus viajes. Es entonces cuando las observaciones y cálculos se traducen y vuelcan (en mapas, croquis, diagramas); cuando el viaje se transforma en texto; o como afirmaba Blumenberg, cuando al libro le es restituida aquella verdad de las cosas que en virtud de la (paradójica) metáfora del libro de la naturaleza le había sido arrebatada ${ }^{3}$.

Nuestro objetivo es indagar en las formas con que Humboldt encaró este segundo viaje, un nostos suyo que también supuso otro desplazamiento, la llegada del Nuevo al Viejo Mundo, una labor que cae de lleno en el ámbito de la transferencia, esto es, de la representación. En cierto sentido, el bicentenario que celebramos ahora no es el de una arribada singular, el de una sola persona, por muy personaje que fuera. Bien mirado, una vez regresado a Europa, era también la propia naturaleza americana la que viajaba con el sabio prusiano para ser expuesta en sus obras, describiendo en cierto sentido un tornaviaje respecto a los viajes colombinos. No en vano, podría decirse que quien ha sido llamado "segundo descubridor de América», lo fue fundamentalmente no por haber ido, sino más bien por haberla traído, capturado y (re)presentado de una manera clásica, una manera largamente celebrada e imitada. Tanto, que se ha hecho común ya hablar de Humboldt como segundo inventor o hacedor de América, sea que nos acojamos a la influencia de O'Gorman en historia de América, a Pratt desde los estudios postcoloniales o incluso a una mirada constructivista en historia de la ciencia ${ }^{4}$.

Sobra decir que el tema es muy ancho y que aquí sólo pretendemos aportar una línea a la ancha literatura que en Humboldt (y no digamos fuera de él) se despliega sobre nuestro objeto, la tensión y la relación entre lo visual y lo lingüístico en la representación científica ${ }^{5}$, entre la imagen y la palabra humboldtianas, esto es, entre esos cuadros y esas escrituras de la Naturaleza que constituyen los dos medios de transporte por excelencia para efectuar los dos trayectos: el del Nuevo Mundo hacia el Viejo y el de la Naturaleza al libro.

En un pasaje bien conocido del Cosmos, el propio Humboldt dejó sentado lo que para él constituían los tres medios para difundir el estudio de la naturaleza:

3 Blumenberg, H. (2000), La legibilidad del mundo, Barcelona, Paidós, pp. 19-23.

4 O'GORMan, E. (1958), La invención de América. El universalismo de la cultura occidental, México, FCE; PRATT, M.L. (1992), Imperial Eyes. Travel Writing and Transculturation, Nueva York; Routledge, Livingstone, D.N. (1992), The Geographical Tradition. Episodes in the History of a Contested Enterprise, Oxford, Blackwell, pp. 137-138.

5 Aunque es un asunto del que por una vía u otra se han ocupado muchas y diversas literaturas, podemos escoger un título - una colección de estudios - en donde nuestro enfoque se reconoce: Lynch, M. y WoOlgar, S. (eds.) (1990), Representation in Scientific Practice, Cambridge Mss., MIT. 
« $1^{\mathrm{a}}$ La descripción animada de las escenas y de las producciones naturales; $2^{\mathrm{a}}$ la pintura del paisaje, desde el momento en que ha comenzado a expresar la fisonomía de los vegetales, su feraz abundancia y el carácter individual del suelo que los produce; $3^{\mathrm{a}}$ el cultivo más extendido de las plantas tropicales y las colecciones de especies exóticas en los jardines y estufas» ${ }^{6}$.

Es la obertura de la primera parte del tomo II, titulada «Reflejo del Mundo exterior en la imaginación del hombre», cuyas primeras palabras advierten al lector de otro tránsito - otra transferencia- de interés también para nuestro tema («De la esfera de los objetos exteriores pasamos a la esfera de los sentimientos»). Y es también el fragmento donde, al enumerar las causas que pueden llevarle a uno hacia el estudio científico de la Naturaleza - las razones que pueden moverle-, menciona las «impresiones fortuitas y en apariencia pasajeras de la juventud». En este apartado distingue de forma genérica el placer de contemplar en los mapas la forma articulada de los continentes y los mares interiores, las imágenes de las palmeras de la Palestina o los cedros del Líbano que contienen las Sagrada Escrituras, etc. A título particular evoca ya los tres ejemplos que en su biografía ilustran los citados tres medios, los tres elementos que le movieron a él en su juventud. Mientras que la visión de los cuadros de Hodges sobre las orillas del Ganges en la casa londinense de Warren Hastings y del colosal drago en la estufa del Jardín Botánico de Berlín armaron el segundo y el tercero, son las pintorescas descripciones de las islas del Mar del Sur a cargo de George Forster las que destaca para ejemplificar el primero, «la descripción animada de las escenas y de las producciones naturales» ${ }^{7}$.

Aunque es propiamente este primer elemento del que nos ocuparemos, resulta evidente la preeminencia de lo visual en la enumeración, la importancia que atribuye a la contemplación de imágenes (naturales o artificiales) en el estímulo hacia las ciencias de la Naturaleza. Ahora bien, es la referida «descripción animada» la que acaparará lo mejor de sus reflexiones, lo que más le preocupa, algo fácil de entender puesto que fue el método de expresión y representación de la naturaleza más practicado por él a lo largo de su vida, e incluso algo fácil de demostrar si se comprueba en términos cuantitativos el desigual desarrollo que a continuación le dedicó en Cosmos a los citados tres medios en los capítulos subsiguientes. En efecto, el capítulo sobre la «literatura descriptiva» - el título que intercambia pero que equivale a «la descripción

6 Humboldt, A. (1874-75), Cosmos. Ensayo de una descripción física del mundo, Madrid, Imprenta de Gaspar y Roig, t II, p. 4.

7 Ibidem, pp. 3-5. 
animada de las escenas»—- merece 65 páginas, mientras que los dos restantes sólo 18 y 9 respectivamente 8 .

Es un lugar común entre los estudiosos y comentaristas explicar la ciencia humboldtiana (su perspectiva, sus inquietudes, sus temas de estudio) apelando a su carácter sintético y global, a su talante verdaderamente universal ${ }^{9}$. Lo que se atribuye como el gran logro de La geografia de las plantas $(1805)^{10}$, a saber, su capacidad para entrelazar variables y fenómenos diversos e integrarlos todos, fundando así un nuevo campo de estudio, la fitogeografía, es también algo aplicable a la voluntad integradora con que maneja y emplea lo visual y lo escrito. El trasiego entre lo uno y lo otro, entre lo que las imágenes dicen y hacen y lo que las palabras expresan y manifiestan, es constante en su obra y de hecho no parecería exagerado afirmar que dicho tráfico constituyó, al menos desde el punto de vista epistemológico, una de sus preocupaciones fundamentales.

Así, por ejemplo, en un trabajo dedicado al pensamiento visual de Humboldt, Anne Marie Claire Godlewska ha defendido que el carácter innovador de su obra reside precisamente en la creación de esas nuevas técnicas de representación ${ }^{11}$. Estamos ante un nuevo lenguaje científico que se despliega en su obsesiva labor experimental con los mapas temáticos o prototemáticos, con gráficos, diagramas, mapas, isolíneas y todo tipo de imágenes científicas que delatan, en efecto, un poderoso esfuerzo por articular un lenguaje visual, un artefacto destinado a grabar y reproducir a través de un solo golpe de vista (un cuadro) la unidad y variedad de los fenómenos naturales. Hay muchos ejemplos de ello, quizás el más elocuente sea la plancha de Bouquet, el espléndido Tableau physique des Andes et Pays voisins, el gráfico pictórico y multidimensional que culmina y compendia La geografia de las plantas.

Se trata de un procedimiento iconográfico que lograr traer y reunir ante el ojo del lector (quizás mejor diríamos el «espectador») toda una serie de ele-

8 Ibidem, pp. 7-71, 72-90 y 90-99.

9 Sobre el concepto de «ciencia humboldtiana», véase DeTtElbaCH, M. (1996), «Humboldtian Science», en JARDine, N., SeCORD, J.A. y SPARY, E.C. (eds.), Cultures of Natural History, Cambridge, Cambridge University Press, pp. 287-304, quien discute y orienta la categoría acuñada en CANNON, S.F. (1978), Science in Culture: The Early Victorian Period, Nueva York, Dawson, pp. 73-111.

10 Evidentemente nos referimos al Essai sur la Geographie des Plantes, cuya primera edición data de 1805 y que citamos en castellano aquí, como el resto de sus obras, para agilizar las cosas.

11 GodLEWSKA, A.M-C. (1999), «From Enlightenment Vision to Modern Science? Humboldt's Visual Thinking», en Livingstone, D.N. \& Withers, C.W.J. (eds.), Geography and Enlightenment, Chicago, University of Chicago Press, pp. 236-281. 
mentos dispersos que no pueden ser apreciados en un lugar concreto o físico. Es decir, con ellos Humboldt consigue ubicar al espectador en una posición imaginaria y abstracta, alejada del escenario natural, un punto de vista donde se condensan sus ideas científicas y desde el cual es posible observar aquello que no es observable sobre el terreno, puesto que procede de su labor intelectual, no de su actividad como naturalista de campo, sino de sus operaciones en el recinto cerrado del estudio. Es entonces cuando se hacen por fin visibles las leyes, relaciones, armonías e intercambios entre fenómenos naturales aparentemente disociados, desvelando así la unidad del cosmos, reproduciéndola (o creándola) de hecho en la mente del espectador.

Pero con ser dichos mapas temáticos, atlas, diagramas y demás un aspecto muy destacado para hablar de la imagen y lo visual en la obra de Humboldt, obviamente no es el único. Tenemos el interés que depositó en la pintura propiamente dicha del paisaje, apartado en el que habría que subrayar hasta qué punto se involucró él mismo en la selección de los artistas que ilustraron su obra, su decisivo paso por Roma o su propio interés por la fotografía. Y por supuesto su contribución a la formación del paisaje americano y la constitución del exotismo, esa categoría que vincula arte, imperio y conocimiento para apresar y representar la naturaleza de las regiones tropicales. Este apartado quizás sea el más desarrollado por la historiografía, ahí donde surgen los nombres de ilustradores suyos de la talla de Pierre-Antoine Marchais o Jean Thomas Thibaut, o donde la obra humboldtiana se erige como un eslabón indispensable entre la pintura de William Hodges y la de Johann Moritz Rugendas, Ferdinand Bellerman o Thomas Ender ${ }^{12}$.

12 La bibliografía que se ha ocupado de los aspectos artísticos (pictóricos) en Humboldt es muy amplia. La propia PRATT (1992) lo hace indirectamente, puesto que su tema (la narrativa imperial y el exotismo) la obliga. Dos grandes visiones de conjunto que ubican la obra humboldtiana en el contexto más amplio de las ilustraciones y representaciones visuales en los viajes de exploración del periodo, son: SMITH, B. (1960), European Vision and the South Pacific, 1768-1850, Oxford, Clarendon Press; y STAFFord, B.M. (1984), Voyage into Substance. Art, Science, Nature, and the Illustrated Travel Account, 1760-1840, Cambridge Mss., MIT. También JACOBS, M. (1995), The Painted Voyage. Art, Travel and Exploration 1564-1875, Londres, The British Museum Press. Específicamente sobre Humboldt, quien quizás ha trabajado más exhaustivamente el tema sea Renate Löschner. Su tesis doctoral: LöSCHNER, R. (1976), Lateinamerikanische Landschaftsdarstellungen der Maler aus dem Umkreis von Alexander von Humboldt, Berlín, Technische Universität Berlin. Ver también GonZÁLEZ, B. (2001), «La escuela del paisaje en Humboldt», en HoLl, F. (ed.), El regreso de Humboldt, Quito, Imprenta Mariscal, pp. 87-90; y REBOCK, S. (2003), «El arte al servicio de la ciencia: Alexander von Humboldt y la representación iconográfica de América», en $51^{\circ}$ Congreso Internacional de Americanistas, «Repensando las Américas en los Umbrales del Siglo XXI», CD-ROM. 
Nuestro interés aquí sin embargo se centra en la «literatura descriptiva», en qué consiste y cómo actua ese medio para difundir el estudio de la naturaleza llamado «la descripción animada de las escenas y las producciones naturales», procedimiento sobre el que Humboldt teorizará sobradamente y, más aún, sabrá poner en práctica en Cosmos y Cuadros de la Naturaleza, sus dos obras fundamentales, la una por sistemática y monumental, la otra precisamente por lo contrario, por sintética y popular.

Los propios títulos son de por sí significativos: Cosmos, la vieja palabra griega cuyo signficado remite doblemente a la noción de orden, pero también a adorno, atributo, embellecimiento (de ahí «cosmética»); y Ansichten, la palabra alemana traducida habitualmente por cuadros, pero que también encuentra justificación en otros términos, así escenas, vistas, visiones, aspectos, apariencias, panorámicas o perspectivas. No está de más la precisión lingüística, puesto que el verbo ansehen expresa una manera muy específica de mirar y ver, un acto que guarda relación con un vocabulario muy empleado por el propio Humboldt: presenciar un espectáculo, contemplar y examinar un escenario o un paisaje ${ }^{13}$.

De nuevo tenemos que su propósito es ubicar al espectador hacia su punto de vista omnicomprensivo, convertirlo en un testigo virtual, hacerle partícipe de su mirada para que pueda presenciar el «espectáculo grandioso de la naturaleza».

Su preocupación por la forma literaria de la exposición no es por tanto una (mera) cuestión de estilo. Muy al contrario, estamos ante la principal herramienta con la que construye su ciencia. Su método narrativo, llamado sucesivamente «literatura», "prosa» e incluso "poesía descriptiva», ha de ser entendido en puridad como el más preciado entre sus künstliche instrumenten, los instrumentos artificiales que siempre le acompañaban en sus excursiones. Con ellos registraba las varibles y mediciones, en última instancia, eran los artefactos que garantizaban la fiabilidad de los datos. Lejos ya del campo de operaciones donde ha registrado y recolectado dichas observaciones y donde por otra parte ha recibido también toda esa gama de sensaciones que desde el mundo exterior se graban en las «profundidades del pensamiento», ahora, en el momento de trasladarlo a un texto, el lenguaje adquiere un status científico indiscutible. Es la herramienta de conocimiento por excelencia. Para producirlo y reproducirlo. Su función en el momento de la representación es similar al que desempeña el barómetro, el sextante o el microscopio en el momento previo de la experimentación.

13 Agradezco a mi colega Barbara Böck, del Instituto de Filología del CSIC, sus observaciones sobre este punto. 
Desde ahí debe entenderse su insistencia en el asunto, la importancia que le concede, la persistencia a la hora de buscar un lenguaje y un método descriptivo que reproduzca y haga visible su magnífica concepción del universo:

«La naturaleza es el reino de la libertad y para pintar vivamente las concepciones y los goces que su contemplación profunda espontáneamente engendra, sería preciso dar al pensamiento una expresión también libre y noble en armonía con la grandeza y majestad de la creación ${ }^{14}$.

Es en el mencionado capítulo sobre la «literatura descriptiva» donde, principal pero no exclusivamente, da cuenta de cuáles son sus propósitos respecto a esta técnica o, casi podríamos decir, tecnología literaria. En otros apartados de Cosmos, comenzando por la propia introducción - lo que delata ya el papel que le confiere-, y por supuesto en Cuadros, abunda en comentarios y reflexiones sobre el particular:

«He procurado hacer ver en el Cosmos, lo mismo que en los Cuadros de la Naturaleza, que la exacta y precisa descripción de los fenómenos no es absolutamente inconciliable con la pintura viva y animada de las imponentes escenas de la creación $»^{15}$.

Aquí y allá la fraseología se reitera. Se trata de operar una doble restitución que afecta al lenguaje científico, al que trata de dotar de un componente visual y animado que le ha sido arrebatado. Esta idea encuentra apoyo por diversos flancos de su pensamiento, heterogéneos en sí pero convergentes en el asunto que nos ocupa.

Nos referimos en primer lugar a la explícita revuelta contra la visión mecanicista y muy particularmente contra el lenguaje experimental que había colonizado las relaciones de viaje y las descripciones geográficas bajo la égida de la ciencia moderna. El siglo de las Luces había asistido a un notable esfuerzo por disciplinar la labor de los viajeros como sujetos capaces de enunciar conocimiento cierto, una tarea que había afectado a todo tipo de prácticas relacionadas con un arte apodémica contemplada cada vez más como una actividad científica, es decir, emparentada con lo que se hacía en un laboratorio (y sobre todo con cómo luego se relataba lo que se había hecho en el recinto cerrado de la experimentación) ${ }^{16}$.

14 Cosmos, t. I, p. 1.

15 Cosmos, t. I, p. IX.

16 Sobre el auge y la imposición del lenguaje experimental, ver LiCOPPE, C. (1996), La formation de la practique scientifique. Le dicours de l'experience en France et en Angleterre (1630-1820), París, La Découverte. En el ámbito de las relaciones de viaje, PIMENTEL (2003). 
Entre estas prácticas quizás una de las prominentes, en efecto, había sido el empleo de una prosa desnuda y transparente, alejada del lenguaje figurativo y del truco de las metáforas, una prosa deudora de las técnicas literarias difundidas desde finales del siglo XVII por instituciones como la Royal Society. Desde este contexto, por ejemplo, se explica que Anders Sparrman, uno de los naturalistas que había acompañado a Cook en su segunda circunnavegación, dejara dicho que todo libro de viajes auténtico y bien redactado era un tratado de filosofía experimental, puesto que también allí el filósofo buscaba la observación genuina y la observación real de las cosas. Desde este contexto, en fin, se explica el afán de los principales exploradores científicos del siglo XVIII por someter sus relaciones al estilo neutro e impersonal del que Bougainville hacía alarde cuando afirmaba que la geografía son hechos y que él carecía en absoluto de educación literaria. Su modelo lingüístico era el de las matemáticas; su maestro, D'Alambert' ${ }^{17}$.

La «ética de la exactitud» - tal y como la han denominado Bourguet y Licoppe $^{18}$ — se había ido imponiendo desde la década de 1730, en la época de las expediciones para medir el grado de meridiano y el auge de los debates en torno a la metrología. La doctrina durante la Ilustración llegó a ser clara en todos los niveles: trigonometría esférica, nomenclatura binomial, hechos neutros, relato experimental. Humboldt recogerá esta herencia. Y lo sorprendente es apreciar cómo no sólo profundizó en ella — sin duda tal «ética de la exactitud» cobrará con el prusiano una dimensión inédita-, sino en cómo, de otra parte, se revolvió contra ella. Es el genio de Humboldt, quien como en tantos otros asuntos alcanza cotas y metas supremas y a menudo opuestas.

Estamos ante la revuelta contra la austeridad y la frialdad de un estilo descriptivo que no recogía sino que amputaba algo sustantivo de la naturaleza, una reacción de la que Humboldt, más que su precursor, se considera su cenit. Así, señala la estela en la que se sitúa. Menciona explícitamente a Rousseau, Buffon, Chateaubriand («mi antiguo amigo»), Playfair, por descontado a Forster y al propio Saint-Pierre, a quien dedicará más de un comentario en distintos pasajes de su obra ${ }^{19}$.

17 Todo este asunto, más detenidamente, en PIMENTEL (2003), pp. 47-91.

18 Bourguet, M.-N. y LiCOPPE, C. (1997), «Voyages, mesures et instruments. Une nouvelle expérience du monde au Siècle des Lumières», en Annales HSS, $\mathrm{n}^{\circ}$ 5, pp. 1115-1151; BOURGUET, M.-N., LiCOPPE, C. y SiBUM, H.O. (eds.), Instruments, Travels, and Science : Itineraries of Precision form the Seventeenth to the Twentieth Century, Londres y Nuava York, Routledge.

19 Cosmos, t. II, pp. 61-62 
Su deuda con el autor de Pablo y Virginia (1788) es realmente significativa, y ha sido comentada a menudo por la crítica ${ }^{20}$. No en vano, la novela sentimental ubicada en la Isla Mauricio que Humboldt afirmó haberle acompañado e inspirado, se abría con la expresión de un deseo que parece él mismo haber querido colmar con su obra:

«Me he propuesto grandes metas en esta obrita — afirmaba Saint-Pierre- - He intentado retratar en ella una tierra y unos vegetales diferentes a los de Europa. Ya han hecho descansar bastante nuestros poetas a sus enamorados a la orilla de los arroyos, en las praderas y bajo el follaje de las hayas. Yo he querido sentarlos a la orilla del mar, al pie de los riscos, a la sombra de los cocoteros, de los plátanos y limoneros en flor. Sólo le faltan a la otra parte del mundo Teócritos y Virgilios para tener de ella unos cuadros al menos tan interesantes como los de nuestra tierra» ${ }^{21}$.

Humboldt, en efecto, aspira a desempeñar este papel. A desarrollar la idea de «cuadros de la naturaleza» que el propio Saint-Pierre había enunciado, a ejecutarlos de hecho. En un texto anterior, el Voyage à l'île de France (1773), el oficial francés ya había cargado contra las descripciones geográficas de su tiempo. Los viajeros no sabían representar los objetos naturales. Sus descripciones de ríos, villas o montañas eran todas similares, tan áridas como las cartas y los mapas. A consecuencia de ello — clamaba Saint-Pierre-, «el Indostán se parece a Europa» ${ }^{22}$.

Muchas de sus expresiones e ideas encontrarán en Humboldt pleno desarrollo. Así, por ejemplo, cuando Saint-Pierre menciona que dichas descripciones carecen de fisonomía, está anunciando uno de los conceptos claves de la narrativa humboldtiana. Otro tanto puede decirse de sus reproches acerca de los resultados que había contraído el lenguaje experimental y la mirada científica ( $\mathrm{A}$ fuerza de naturalizar con las artes, la naturaleza nos ha devenido extranjera» ${ }^{23}$ ); o sobre la incapacidad de los botánicos para ir más allá de la descripción sistemática de la morfología (linneana) de las plantas:

20 CAstrillón, A. (2000), Alejandro de Humboldt, del catálogo al paisaje, Medellín, Editorial Universidad de Antioquía, pp. 60, 91 y 192; PUIG-SAMPER, M.A. y REBOK, S. (2003), «Introducción: Alejandro de Humboldt y los 'Cuadros de la Naturaleza' «, en HuMBOLDT, A. de (ed. 2003), Cuadros de la Naturaleza, Madrid, Los libros de la Catarata, pp. 13-38, p. 24; PIMENTEL (2003), pp. 291-329.

21 Bernardin de Saint-Pierre, J.-H. (ed. 1989), Pablo y Virginia, Madrid, Cátedra, p. 51. Las cursivas, nuestras.

22 Bernardin De Saint-Pierre, J.-H. (ed. 1983), Voyage à l'île de France. Un officier du roi à lîle Maurice, 1768-1770, París, La Découverte, 1983, p. 254.

23 Ibidem, p. 253. 
«¿Hablan de una planta? Detallan sus flores, sus hojas, su corteza, sus raíces. Pero nadie da cuenta de su porte, su apariencia, su elegancia, su rudeza o su gracia. Por tanto, la semejanza de un objeto depende de la armonía de todas sus partes y teniendo la medida de todos los músculos de un hombre no se obtiene su retrato» ${ }^{24}$.

Saint-Pierre, en suma, había delatado la insuficiencia de un método descriptivo que dejaba fuera de la representación asuntos como la fisionomía, el color, la emotividad, las relaciones entre los fenómenos naturales y el mundo de las sensaciones, el propio acto de la contemplación. «El arte de representar la naturaleza - dejó dicho- es tan nuevo que ni los mismos términos han sido inventados» ${ }^{25}$. En el original rendre: representar, traducir, trasladar, aquello que según hemos visto designa la principal ocupación de los viajeros; pero también expresar, comunicar, transmitir, dimensiones que pertenecen a esa misma operación y que Humboldt desplegará en todo su alcance en un proyecto retórico y de conocimiento, un programa armado alrededor de esta tarea: vivificar el lenguaje científico para devolverle precisamente la vida a la naturaleza ${ }^{26}$.

Con ser importante, sin embargo el de Saint-Pierre no es el único ejemplo a seguir. Dicha restauración tiene un referente más cercano y otro mucho más lejano. Como es sabido, Humboldt destacará repetidas veces a Goethe como máximo exponente a la hora de reivindicar la poesía descriptiva, una reivindicación especialmente «legítima» en Alemania, una nación y una lengua a las que, por otra parte, les está destinada la empresa de recuperar un legado antiguo, el de aquella cultura de la que proceden los lenguajes fundacionales del cosmos:

«¿Qué pueblo meridional no ha de envidiarle [a Alemania] el gran maestro de la poesía cuyas obras todas respiran un sentimiento de la naturaleza tan profundo, Los sufrimientos del joven Werther, como los Recuerdos de Italia, la Metamorfosis de las Plantas como las Poesías varias? ¿Quién ha invitado con más elocuencia a sus conciudadanos «a resolver el enigma sagrado del universo», a renovar la alianza que en la infancia de la humanidad reunía para una obra común a la filosofía, la física y la poesía?» ${ }^{27}$.

24 Ibidem, p. 254.

25 Ibidem.

26 En efecto, «todo cuanto tiende a reproducir la verdad de la naturaleza da nueva vida al lenguaje», subraya en un pasaje de Cuadros especialmente revelador. Es el capítulo dedicado a la vida nocturna de los animales en las selvas del Nuevo Mundo, donde subraya que «la investigación constante de esta verdad es el fin de toda descripción que tenga por objeto la naturaleza». Cuadros, pp. 209-216, p. 210.

27 Cosmos, t. II, pp. 70-71. 
Se refiere a Grecia, obviamente, y está citando un fragmento de La Metamorfosis de las plantas de Goethe (1790), el poema que le dedicó a Christiane Vulpius, con quien se casó el escritor tiempo después. Merece la pena reproducir los versos:

«Te disturba, oh amada, la mezcla de miles de flores aquí y allá en el jardín; muchos nombres escuchaste, y siempre suplanta, con bárbaro sonido, el uno al otro en el oído. Todas las formas son análogas y ninguna se asemeja a la otra; así indica el coro una ley oculta, un sagrado enigma. Oh, si yo pudiese, querida amiga, transmitirte al instante la feliz palabra que lo desvela! $\rangle^{28}$.

La identidad y diversidad de las formas, la ley oculta, el sagrado enigma, la feliz palabra que lo desvela: todo ello encuentra amplia resonancia en el horizonte intelectual humboldtiano, vertebrado por esa búsqueda de la renovación de la alianza entre filosofía, física y poesía, una concepción que a su vez determina la búsqueda y el empleo de un lenguaje descriptivo (una herramienta, una tecnología literaria) que fabrique por sí mismo dicha alianza. No es superfluo recordar aquí que la gran reforma del conocimiento de finales del siglo XVII también había supuesto una reforma del lenguaje que había tenido mucho de recuperación y depuración. Pero lo que en tiempos de Comenius, Locke o Sprat había sido un movimiento dirigido a la restauración de un lenguaje adámico — de ahí que el acento se pusiera en la pureza y brevedad primitivas, que fuera ensalzada la lengua de los artesanos y los comerciantes-; ahora, en los días finales de la Aufklarung y la crisis del Sturm und Drang, el lenguaje a recuperar (y con él su ciencia) no era el del primer hombre, sino el de la que comenzaba a ser vista como la «primera cultura». La infancia de la humanidad ahora resultaba ser Grecia y no la de los primeros padres.

Esto explica hasta qué punto la toría descriptiva humboldtiana se alce contra la precisa nomenclatura linneana, contra la severa prosa de los viajeros marcados por la impronta matemática y mecanicista que había tenido la Revolución Científica. Empleará Humboldt dichos lenguajes, por descontado, tienen sus cometidos. Pero no alcanzan para lograr el más elevado: rendir cuenta, transmitir toda la armonía del cosmos y el propio goce de la contemplación; recuperar la propia idea de physis, una natura naturans y no más aquella natura naturata, una naturaleza objetivada y ajena al (y del) hombre.

28 La metamorfosis de las plantas en Goethe, J.W. (ed. Diego Sánchez Meca, 1997), Teoría de la naturaleza, Madrid, Tecnos, pp. 30-139, p. 83. En realidad la poesía fue escrita en 1798 y añadida al texto en su edición de 1817. 
Es seguramente en Cuadros donde mejor se aprecian estos principios, donde logrará «reproducir en el lector la antigua comunión con la naturaleza». Asumiendo la voz de un narrador omnisciente, un «papel semidivino» ${ }^{29}$, este Lucrecio o Virgilio del Nuevo Mundo formaliza las tres imágenes canónicas del paisaje americano destinadas a perdurar: la selva tropical, las vasta mesetas interiores y las grandes cordilleras andinas. Todas ellas están dominadas por la estética de lo sublime, la categoría teorizada entre otros por Burke y Kant, y de la que ya nos encargamos en otro lugar ${ }^{30}$. Las tres también suponen la formalización de una escala novedosa, el paisaje, una noción alejada del catálogo de los herborizadores, tal y como defiende desde su mismo título la sistemática investigación de Alberto Castrillón sobre este asunto ${ }^{31}$.

$\mathrm{Su}$ predilección por la montaña encuentra doble justificación por la vía estética así como por razones vinculadas a su propia noción de cuadro. De ahí el lugar que ocupan en su narrativa y en su ciencia el Chimborazo y el (incompleto) ascenso que acometió a su majestuosa cúspide. Allí se precipitaban la misma idea de lo sublime en su mejor expresión; allí se derramaban también todas las relaciones, variables y gradaciones de la geografía de las plantas. Era una visión sintética, un monumental cuadro que recogía como ningún otro la riqueza y variedad de los fenómenos naturales ${ }^{32}$.

La variedad y la uniformidad, la diversidad y la unidad: tal vez sea este su tema dilecto. Es un asunto que afecta a la fisonomía del paisaje, a su voluntad de fijar el arquetipo del paisaje (andino, tropical, desértico o meseteño). Humboldt persigue constreñir cuáles son sus rasgos primordiales tal y como Goethe había buscado trazar los perfiles de esa forma ideal que era la planta arquetípica (Urpflanze). Visto así, podemos apreciar la sintonía entre las dos investigaciones. Ambas se dirigen en última instancia a registrar la estabilidad y el cambio, la permanencia y la transformación de las formas orgánicas e inorgánicas. Es el sagrado enigma, en fin, la vida.

Resulta esclarecedor en este sentido la historia relatada en La fuerza vital o el genio rodio, el texto que Humboldt incluye en Cuadros y que había publicado en 1795 en la revista del círculo de Jena, Las Horas (Die Horen) ${ }^{33}$. Tras

29 PrATt (1992), p. 124.

30 Pimentel (2003), pp. 191-200.

31 CASTRILLÓN (2000).

32 Pimentel (2003), pp. 179-211.

33 Cuadros, pp. 283-393. Sobr el círculo de Jena, Morgan, S.R. (1990), «Schelling and the origins of his Naturphilosophie», en CunNinghaM, A. y JARDINE, N. (eds.), Romanticism and the Sciences, Cambridge, Cambridge University Press, 1990, pp. 25-38. 
la leyenda que pone en boca de Epicarmo se escondía en realidad un tema al que Humboldt, como naturalista, le concede toda su gravedad. La pintura que alberga el Poecilum de Siracusa representa al genio rodio, un muchacho que porta una antorcha y con una mariposa sobre su espalda. Su significado, sin embargo, es objeto de debates y pesquisas interminables entre los filósofos. Sólo encontrará explicación cuando aparece una segunda pintura sobre el mismo tema pero con el genio desprovisto de vida, la mariposa ha volado, la antorcha yace en el suelo sin luz. Es de nuevo el sagrado enigma, el misterio del interminable trasiego entre la materia orgánica y lo inerte, la confirmación de que para explicar la vida ha de acudirse a su opuesto, la muerte.

Aquí y allá el tema de la fuerza vital adquiere gran relieve, una importancia que es al tiempo filosófica, estética, literaria y científica, campos que Humboldt renuncia a escindir, pese a que la fractura kantiana acaba de consolidar aquello que la Revolución Científica llevaba anunciando desde hacía tiempo. Para entender al sabio prusiano, por tanto, no cabe hablar de intereses y objetivos científicos, por un lado, y de intereses y objetivos literarios o filosóficos por otro. Son todos lo mismo. Su búsqueda es universal, afín en este sentido a las que habían emprendido Goethe, Novalis, Schelling o Schiller. Tratar «la física como un arte», por ejemplo, era un lema adoptado por el círculo de Jena y otros Naturforscher (investigadores de la naturaleza) comprometidos de una manera u otra con la Naturphilosophie de la época. De hecho fue el título de una lección impartida por Ritter allá por 1806 en Munich ${ }^{34}$.

Precisamente en una carta a Schiller, fechada en 1794, Humboldt le felicitaba de que no hubiera excluido a las ciencias naturales de su proyecto ${ }^{35}$. En contrapartida le aseguraba que él mismo jamás había esperado de una empresa literaria otra cosa distinta de la que Schiller esperaba de la suya propia. Arremetía a continuación contra los métodos de representación al uso en historia natural, contra los archivistas Registratoren de la naturaleza. «Es menester — afirma Humboldt - buscar algo más elevado», algo que es preciso re-

34 SCHAFFER, S. (1990), "Genius in Romantic natural philosophy», en CUNNINGHAM y JARDINE (eds.), op. cit., pp. 82-98, p. 91. También comenta Schaffer «El genio rodio» de Humboldt, y en general el tema del genio en el Romanticismo, oponiéndolo al concepto de ingenio, dominante en la ciencia moderna del siglo XVII. Sobre el tema del genio también PESET, J.L. (1999), Genio y desorden, Valladolid, Cuatro, pp. 58-64, donde trata el papel creador y demoledor del Fausto de Goethe, otra versión, en cierto sentido, de la oposición vida-muerte que comentamos.

35 La carta entera reproducida en Minguet, C. (1985), Alejandro de Humboldt, historiador y geógrafo de la América española (1799-1804), México, UNAM, vol. I, p. 89. 
descubrir, tarea en la que Aristóteles y Plinio, sus descripciones animadas de la naturaleza, constituyen el referente ineludible.

Descripción animada, pintura animada de las escenas naturales, retrato animado de los cuerpos orgánicos: la palabra se reitera una y otra vez. ¿Qué significa? ¿A qué se refiere? Responder a esta pregunta es en verdad ir hacia el corazón del asunto que estamos tratando, el nexo entre la imagen y la palabra, entre la vista y la escritura. Y significa volver a la vieja doctrina aristotélica sobre la poética, allí donde el concepto de poiesis remite a la nación de hacer, fabricar, producir, y el de mimesis al de imitar, representar.

«Digo que las palabras pintan cuando significan las cosas en acción» ${ }^{36}$, rezaba el enigmático pasaje del estagirita sobre el que Paul Ricoeur levantó La metáfora viva ${ }^{37}$. Y hablando de Homero, «el de la palabra alada», añadía Aristóteles: "Todas estas palabras hacen que las cosas se muevan y vivan, pues la acción es el movimiento» ${ }^{38}$.

Leyendo Cuadros de la Naturaleza se puede comprobar hasta qué punto Humboldt puso en práctica esta vieja preceptiva. Escrita en alemán, por supuesto, es quizás su obra más personal y sin duda la más popular, la más volcada sobre la dimensión comunicativa y transmisora de la ciencia. Emplea una prosa poética majestuosa, cuyo movimiento reproduce y recoge los fenómenos y paisajes naturales, sus propios movimientos; esto es, según acabamos de ver, una prosa que poetiza y mimetiza la naturaleza y su dinamismo. De las pampas meridionales a los llanos de Venezuela; de las estepas asiáticas a los desiertos africanos; desde las cordilleras andinas a las Montañas de la Luna o al Atlas; desde el Chimoborazo a la selvas del Orinoco: la descripción se desplaza de un lado al otro del globo, provocando un efecto panorámico, cinematográfico en cierto sentido. Su prosa, en efecto, busca imitar y fabricar el propio dinamismo que Humboldt detecta por doquier, en la vida de las plantas, en el interior de los volcanes, en la superficie de la tierra:

«Todo anuncia un mundo de fuerzas orgánicas en movimiento. En cada matorral, en la corteza agrietada de los árboles, en la tierra que cavan los himenópteros, la vida se agita y se hace oír como una de las mil voces que envía la naturaleza al alma piadosa y sensible del hombre ${ }^{39}$.

\footnotetext{
36 ARISTÓTELES (ed. Alberto Bernabé, 1988), Retórica, Madrid, Alianza, III, 11, 1411 b 24-25.

37 Ricoeur, P. (1975), La metáfora viva, Madrid, Ediciones Europa.

38 Retórica, III, 11, 1412 a 10.

39 Cuadros (ed. 2003), p. 216.
} 
Pintar la naturaleza y ponerla en movimiento, por consiguiente, son los grandes objetivos de su literatura descriptiva, una técnica que nos permite apreciar aquí la otra vertiente de su «pensamiento visual». La vida se agita y le habla: Humboldt tratará de transferir esa agitación y esa voz. Y para ello experimentará en la búsqueda de fórmulas expresivas y retóricas capaces de traducirlas y representarlas.

Concluyamos, pues, con una imagen. Era Goethe, según hemos visto, quien hablaba de transmitir la feliz palabra que desvelara el sagrado enigma. Esta y no otra parece haber sido también la codiciada pieza de la gran investigación humboldtiana. No por casualidad le homenajea a Goethe dedicándole la edición alemana de La geografía de las plantas (1807). Preside el frontispicio de esta edición un grabado singular ${ }^{40}$. Figura en él la estatua de una diosa antigua, una Isis o Artemisa polymastos (una naturaleza nutricia y reproductora, con múltiples pechos) de resonancias egipciacas y kircherianas ciertamente $^{41}$. Abajo, apoyada en su pie, La Metamorfosis de las plantas. Junto a la diosa es Apolo, el espíritu de la poesía, quien le quita el velo que la cubre, quien literalmente la desvela.

Es una gran representación de la aletheia, el desvelamiento de la verdad, que al final de las Luces parece apuntar a Grecia como para recordar el papel que la «feliz palabra», la poesía misma, desempeña en las ciencias de la naturaleza $^{42}$. Y es también, creemos, otra prueba más que revela la comunión íntima que en Humboldt existe entre lo que las imágenes dicen y lo que las palabras hacen ver: entre los cuadros y las escrituras de la naturaleza.

40 Nicolson, M. (1990), «Alexander von Humboldt and the geography of vegetation», en CUNNINGHAM y JARDINE, op. cit., pp. 169-189, p. 178, también comenta el grabado. Agradezco en todo caso al profesor Ricardo Olmos, Instituto de Historia, CSIC, sus comentarios y conocimientos sobre el significado de esta imagen.

41 En efecto, la misma imagen aparece en la obra de Athanasius Kircher, el gran polímata del siglo XVII: en el Oedipus aegyptiacus I, p. 190.; y en el frontispicio del tomo II del Mundus subterraneus. Se trata de la diosa de la naturaleza, una Isis fundida con Artemisa o Cibeles, un venus sincrética que en todo caso siempre aparece identificada como una Magna Mater Naturae. Ver Gómez DE LiAÑo, I. (2001), Athanasius Kircher. Itinerario del éxtasis o las imágenes de un saber universal, Madrid, Siruela, pp. 213 y 426.

42 Sobre el papel del imaginario egipcio y clásico en la obra de Humboldt, ver LUBRICH, O. (2003), «Egipcios por doquier: Alejandro de Humboldt y su visión orientalista de América», en Revista de Occidente, $\mathrm{n}^{\circ}$ 261, pp. 75-102; y LuBRICH, O. (2001), " 'Como antiguas estatuas de bronce'. Sobre la disolución del clasicismo en la relación histórica de un viaje a las regiones equinocciales del Nuevo Mundo, de Alejandro de Humboldt», en Revista de Indias, vol LXI, núm. 223, pp. 749-766. 


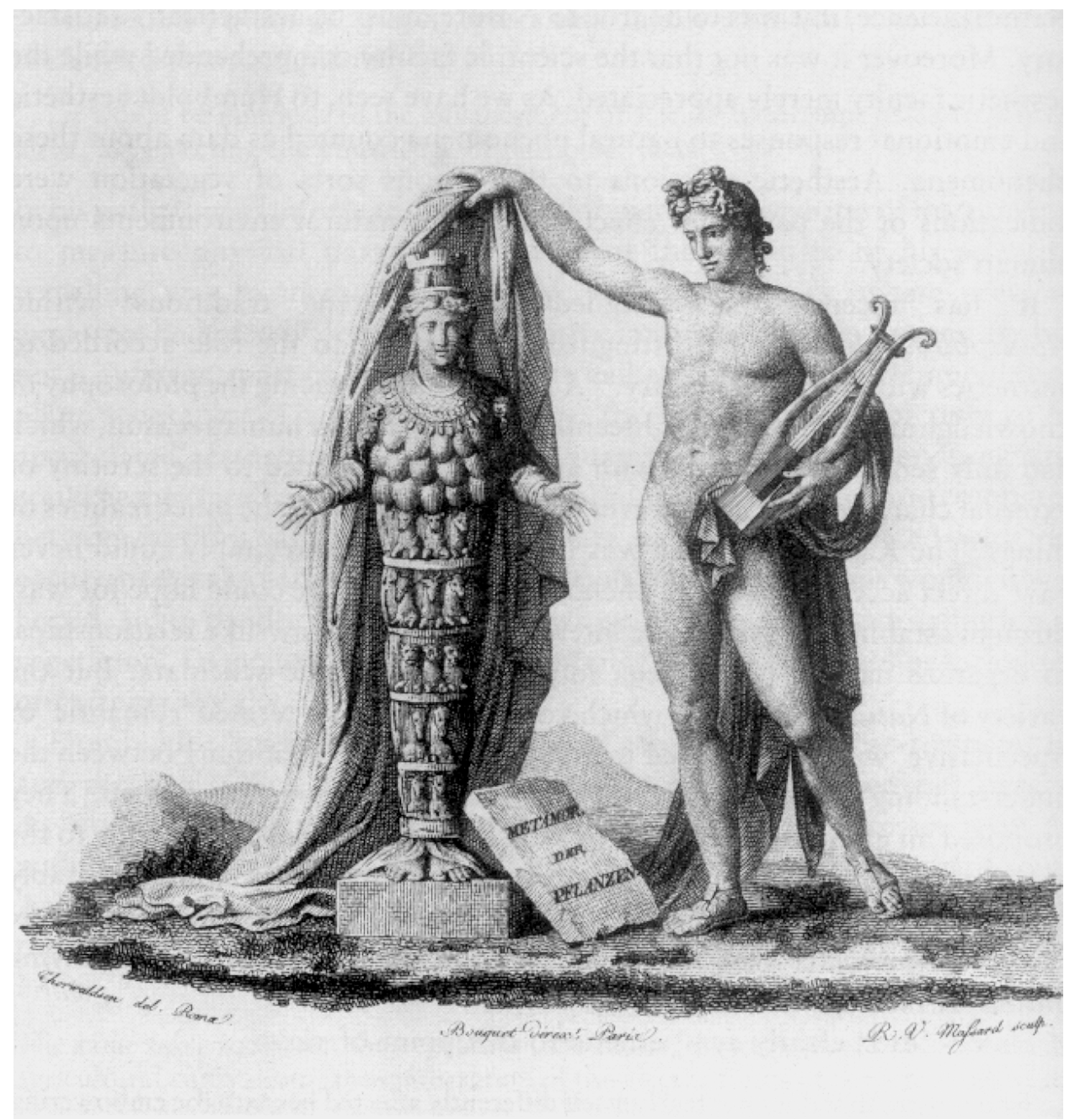

El espíritu de la poesía (Apolo) desvela el misterio de la naturaleza (Isis). Edición alemana del Ensayo sobre la geografía de las plantas (1807) 